\title{
Sérothérapie anti-ulcéreuse
}

Parmi les traitements à prétention pathogénique de l'ulcère gastro-duodénal, une seule thérapeutique, à notre connaissance, tiient comptie jusqu'iei de la périodieité spéciale de la maladie, de Tapparition brusque et de la cessation spontanée des «poussées 》 douloureuses; elle consiste à assimiler $\Gamma$ ulcère à ulne ,affection de mature allergique, et $5 / 8 c_{1}^{\prime}$ hierchei à combattre cette reaction par des medicaments ooimme les ant $1 / 8$ ista-miniques de synthèse.

Voici une nouvelle proposition séduisante, qui fait appel aux differences existaint vraisemblablem.e:nt dans le serum des ulcéreux pendant les périodes douloureusies ou lors des remissions. Aussi R. Carvaíllo préconise-t-il (Arch, malad. appar. digest.; 36, p. 285, mai-juin 1947) Tutilisation du serum prélevé chez des malad\&s dans les fours qui suivent la crise ulcéreuse ( $\mathrm{du} 5^{\circ}$ au $15^{\circ}$ jour après la cessation de la douleur) et traité avec les precautions d'usage pouîr le serum de convalescemt. Le traite $\pi^{3 / 4} / 4$ ent cons $1 / 8$ ste en une injection sous-cutanée de $10 \mathrm{cc}$. II ste produit parfois une réactjioin ortiée looale, et souvent une recrudescence passagcre des douleu|rs épigastriques, qui cèdent ensuite au bout de 24 heures pour ne plus reparaître.

48 malades ont été traités de la sorte avec les résultats suivants: 28 ameliorations dès la premiere injection, avec absence de douleurs pendant plusieurs miois; clh $\odot \mathrm{z} 15$ malades, une rechute les jours suivamits «ixigea une seconde injection (après uin intervalle $\mathrm{d}^{1 / 8} / 8$ e semaiine) pour amener la sedation complete; trois cas exigèrent une troißième injection, et cinq furent des échecs (provenant de doses insuffisantes ou de serum trop ancien).

Comme dans toute thérapeaitique anti-ulcércuise, l'avenir seul nous fournira le recul suffisiant pour juge',r la valeur de cette iméthode nouvelle. Carvaillo reconinaît une proportion de disparition des signes radiologiques s'élevant à $55 \%$ des cas seulement; par contre, à condition de procéder à l'in-jection de serum dès le debut $\left(3^{\circ}\right.$ ou $4^{\circ}$ jour $)$ de la crise, il 